\title{
Konsentrasi Geografis, Ukuran Perusahaan, Tipe Industri dan Pengungkapan Corporate Social Responsibility
}

\author{
Ni Wayan Pitriyani ${ }^{1}$ \\ Fakultas Ekonomi dan Bisnis \\ Universitas Udayana, Indonesia
}

\author{
Dewa Gede Wirama² \\ Fakultas Ekonomi dan Bisnis \\ Universitas Udayana, Indonesia
}

\begin{abstract}
Surel : pitriyani716@gmail.com
ABSTRAK

Penelitian ini menganalisis pengaruh konsentrasi geografis, ukuran perusahaan, dan tipe industri pada pengungkapan corporate social responsibility. Pengungkapan corporate social responsibility merupakan salah satu media yang dipakai untuk memperlihatkan kepedulian sosial perusahaan guna mempertahankan legitimasi dari masyarakat. Penelitian ini dilakukan pada perusahaan yang terdaftar di Bursa Efek Indonesia dari tahun 2016 sampai 2018. Sampel berjumlah 46 perusahaan dengan 138 amatan. Data dianalisis menggunakan regresi linear berganda. Hasil penelitian menemukan bahwa konsentrasi geografis dan ukuran perusahaan memiliki pengaruh positif, sedangkan tipe industri tidak memiliki pengaruh pada pengungkapan corporate social responsibility. Hasil penelitian ini memberikan bukti empiris berkaitan dengan validitas teori legitimasi serta dapat digunakan sebagai bahan pertimbangan dalam pengambilan keputusan untuk pemangku kepentingan.
\end{abstract}

Kata Kunci: Pengungkapan CSR; Konsentrasi Geografis; Ukuran Perusahaan; Tipe Industri.

\section{Geographical Concentration, Company Size, Industry Type and Corporate Social Responsibility Disclosure}

\section{ABSTRACT}

This study analyzed the effect of geographic concentration, company size, and industry type on corporate social responsibility disclosure. Corporate social responsibility disclosure is one of the media to show the company's social care to maintain the legitimacy of the community. This research was conducted on companies listed on the Indonesia Stock Exchange from 2016 to 2018. Samples amounted to 46 companies with 138 observations. Data were analyzed by multiple linear regression. Based on the results of the analysis found that geographic concentration and company size have a positive effect, while the type of industry does not affect the disclosure of corporate social responsibility. The results of this study provide empirical evidence relating to the validity of the theory of legitimacy and can be used as a consideration in decision-making for stakeholders.

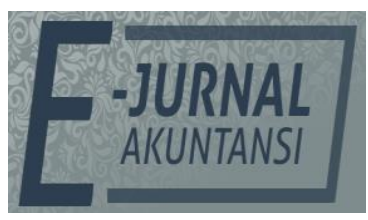

e-ISSN 2302-8556

Vol. 31 No. 1

Denpasar, Januari 2021

Hal. 208-219

DOI:

10.24843/EJA.2021.v31.i01.p16

PENGUTIPAN:

Pitriyani, N.W., \& Wirama,

D.G. (2021). Konsentrasi Geografis, Ukuran

Perusahaan, Tipe Industri dan Pengungkapan Corporate Social Responsibility. E-Jurnal Akuntansi, 31(1), 208-219

RIWAYAT ARTIKEL: Artikel Masuk:

11 Juni 2020 Artikel Diterima:

6 Juli 2020

Keywords: $\quad$ CSR Disclosure; Geographic Concentration; Company Size; Industry Type.

Artikel dapat diakses : https://ojs.unud.ac.id/index.php/Akuntansi/index 


\section{PENDAHULUAN}

Sebuah Perusahaan didirikan dengan harapan dapat bertahan untuk jangka waktu yang lama. Semakin lama sebuah perusahaan berdiri maka dampak yang akan ditimbulkan bagi lingkungan juga semakin besar (Suprasto \& Haryanti, 2019). Untuk menjamin kelangsungan hidup dalam jangka panjang maka perusahaan harus memperoleh legitimasi dari masyarakat. Pengungkapan corporate social responsibility (CSR) merupakan sarana yang dapat dipilih untuk menunjukkan kepedulian perusahaan guna mendapat legitimasi dari masyarakat (Kusumawardani \& Sudana, 2017). CSR merupakan konsep yang menerangkan tanggung jawab perusahaan terhadap Stakeholder maupun pihak lain yang merasakan dampak dari beroperasinya perusahaan (Oktariani \& Mimba, 2014). Salah satu usaha pemerintah untuk meningkatkan kepatuhan perusahaan dalam mengungkapkan tanggung jawab sosial dilakukan oleh Kementerian Lingkungan Hidup melalui program penilaian peringkat kinerja perusahaan yang disingkat PROPER.

PROPER adalah program andalan Kementerian Lingkungan Hidup yang berbentuk kegiatan pengawasan serta pemberian insentif dan disinsentif bagi penanggung jawab usaha. Anugerah PROPER diberikan untuk memotivasi perusahaan agar taat pada peraturan lingkungan hidup dan memiliki keunggulan lingkungan melalui konsep pembangunan berkelanjutan dalam proses produksi dan jasa, implementasi sistem manajemen lingkungan, penghematan energi, konservasi sumber daya alam dan pelaksanaan usaha yang beretika serta bertanggung jawab terhadap masyarakat melalui program pengembangan masyarakat (https:/ / PROPER.menlhk.go.id, diakses 02 Oktober 2019)

Penilaian diberikan dalam bentuk peringkat mulai dari peringkat "emas" (terbaik) sampai "hitam" (terburuk). Tabel 1 menunjukkan bahwa masih sangat sedikit perusahaan yang mendapat peringkat emas, yang artinya masih sedikit perusahaan yang dianggap berhasil melakukan pengelolaan lingkungan secara berkelanjutan. Beberapa perusahaan ternyata masih melakukan pelanggaran, yang terlihat dari masih adanya perusahaan yang memperoleh peringkat hitam.

\section{Tabel 1. Penilaian PROPER}

\begin{tabular}{lrrr}
\hline Peringkat & \multicolumn{3}{c}{ Tahun } \\
\cline { 2 - 4 } & 2016 & 2017 & 2018 \\
\hline Emas & 12 & 19 & 20 \\
Hijau & 172 & 150 & 155 \\
Biru & 1.422 & 1.486 & 1.454 \\
Merah & 284 & 130 & 241 \\
Hitam & 5 & 1 & 2 \\
Jumlah & 1.895 & 1.786 & 1.872 \\
\hline
\end{tabular}

Sumber: https://PROPER.menlhk.go.id, diakses 02 oktober 2019.

Masing-masing perusahaan mempunyai motivasi yang berbeda dalam melakukan pengungkapan CSR. Perbedaan motivasi ini dipengaruhi oleh kondisi dan lingkup kegiatan perusahaan yang berbeda satu sama lain serta bergantung juga dari masyarakat di sekitar lokasi perusahaan didirikan.

Saat ini perusahaan tidak hanya berkonsentrasi untuk beroperasi di satu wilayah atau di satu negara saja, tetapi sudah mulai mengembangkan bisnisnya dengan mendirikan anak perusahaan di negara lain atau kita kenal dengan 
perusahaan multinasional. Perusahaan multinasional mengalami tekanan yang lebih besar untuk bertahan dan beradaptasi dengan lingkungan yang berbeda di setiap negara. Perusahaan multinasional juga membutuhkan strategi untuk secara efektif merangkul budaya dan tradisi asing ke dalam praktik kerja agar dapat tetap bertahan di pasar global (Titisari, 2017).

Di sisi lain perusahaan besar mempunyai lebih banyak kegiatan operasional, di mana dampak yang ditimbulkan juga lebih besar sehingga lebih diperhatikan oleh publik daripada perusahaan kecil (Hidayat, 2017). Situasi ini membuat perusahaan besar menghadapi tekanan yang lebih besar untuk mengungkapkan CSR.

Perusahaan high profile merupakan perusahaan yang memiliki tingkat risiko lingkungan, sosial, politik, dan persaingan yang tinggi sehingga perusahaan ini akan mendapat lebih banyak perhatian dari publik (Anggraeni \& Djakman, 2018). Bagi perusahaan yang termasuk dalam industri high profile mengomunikasikan kegiatan CSR menjadi hal yang penting (Tetrevova, 2018).

Penelitian yang dilakukan oleh Aksak \& Duman (2016) dan Kopel et al. (2018) menemukan bahwa perusahaan multinasional mempunyai pengaruh pada pengungkapan CSR sedangkan Bawono \& Haryanto (2015) menemukan perusahaan multinasional tidak memengaruhi pengungkapan CSR. Adapun penelitian yang menemukan ukuran perusahaan berpengaruh positif pada pengungkapan CSR, dilakukan oleh Respati \& Hadiprajitno (2015), Issa (2017), serta Indrayenti \& Jenny (2018). Hasil ini bertentangan dengan penelitian Wiyuda \& Pramono (2017), serta Elshabasy (2018) yang menemukan ukuran perusahaan tidak berpengaruh pada pengungkapan CSR. Penelitian tentang pengaruh tipe industri pada pengungkapan CSR dilakukan oleh Dewanti \& Widyadmono (2018) dan Widiastuti et al. (2018) menemukan adanya pengaruh positif, sedangkan AlAjmi et al. (2015) serta Al-Gamrh \& AL-Dhamari (2016) menemukan bahwa tipe industri tidak memiliki pengaruh pada pengungkapan CSR.

Teori legitimasi adalah suatu konsep tentang kontrak sosial di mana perusahaan setuju untuk melakukan tindakan sosial tertentu agar perusahaan dapat diterima oleh masyarakat sehingga kelangsungan hidup perusahaan terjamin (Gunawan \& Apriwenni, 2019). Dowling \& Pfeffer (1975) menyebutkan bahwa organisasi berupaya membuat kesesuaian antara nilai-nilai sosial yang terdapat pada aktivitasnya dengan nilai-nilai perilaku yang ada pada sistem sosial masyarakat, di mana organisasi menjadi bagian sistem tersebut. Perusahaan akan mendapat legitimasi dari masyarakat apabila terjadi keselarasan antara nilai-nilai perusahaan dengan nilai-nilai yang terdapat dalam sistem sosial masyarakat.

Perusahaan multinasional cenderung memiliki informasi CSR yang lebih luas dikarenakan persaingan yang lebih ketat sehingga kelangsungan hidup perusahaan tidak hanya dari keuntungan tetapi juga harus memiliki keunggulan di bidang sosial agar legitimasi tetap terjaga. Di samping itu perusahaan multinasional juga memiliki banyak stakeholders dan berada di lebih dari satu negara sehingga perlu melakukan pengungkapan CSR yang lebih luas. Hal ini sesuai dengan penelitian Aksak \& Duman (2016). Berdasarkan uraian, hipotesis pertama yang akan diuji yaitu sebagai berikut.

$\mathrm{H}_{1}$ : Konsentrasi geografis berpengaruh positif pada pengungkapan corporate social responsibility. 
Perusahaan besar memiliki aktivitas yang lebih kompleks dan dampak yang lebih luas bagi lingkungan sehingga kegiatan perusahaan ini akan lebih disoroti oleh masyarakat. Perusahaan besar perlu mengungkapkan corporate social responsibility untuk mendapat legitimasi dari masyarakat (Suprasto \& Haryanti, 2019). Hal ini terbukti dari hasil penelitian Indraswari \& Astika (2015), Riantani \& Nurzamzam (2015), serta Waluyo (2017) yang menemukan ukuran perusahaan memiliki pengaruh positif pada pengungkapan corporate social responsibility. Berdasarkan uraian, hipotesis kedua yang akan diuji yaitu sebagai berikut.

$\mathrm{H}_{2}$ : Ukuran perusahaan berpengaruh positif pada pengungkapan corporate social responsibility.

Perusahaan yang high profile ialah perusahaan yang akan mendapat perhatian yang lebih besar dari publik karena berpotensi memiliki tingkat risiko lingkungan, sosial, politik dan persaingan yang tinggi (Anggraeni \& Djakman, 2018). Perusahaan pertambangan adalah salah satu contoh perusahaan yang masuk kategori high profile karena memiliki risiko lingkungan yang tinggi. Berbeda dengan perusahaan low profile yang memiliki tingkat risiko lingkungan, sosial, politik dan persaingan yang rendah sehingga tidak terlalu diperhatikan oleh masyarakat (Urmila \& Mertha, 2017). Contoh perusahaan low profile yaitu perusahaan properti karena perusahaan ini memiliki tingkat risiko lingkungan yang rendah. Untuk menjaga legitimasi, perusahaan high profile akan melakukan pengungkapan informasi CSR yang lebih banyak karena perusahaan ini memperoleh perhatian yang lebih besar. Hal ini dibuktikan oleh penelitian Dewanti \& Widyadmono (2018) dan Susilowati et al. (2018) yang menemukan bahwa tipe industri memiliki pengaruh positif pada pengungkapan corporate social responsibility. Berdasarkan uraian, hipotesis ketiga yang akan diuji yaitu sebagai berikut.

$\mathrm{H}_{3}$ : Tipe industri berpengaruh positif pada pengungkapan corporate social responsibility.

Ketiga hipotesis penelitian disajikan dalam Gambar 1. Gambar tersebut menunjukkan variabel dan hubungan antar variabel dalam penelitian ini.

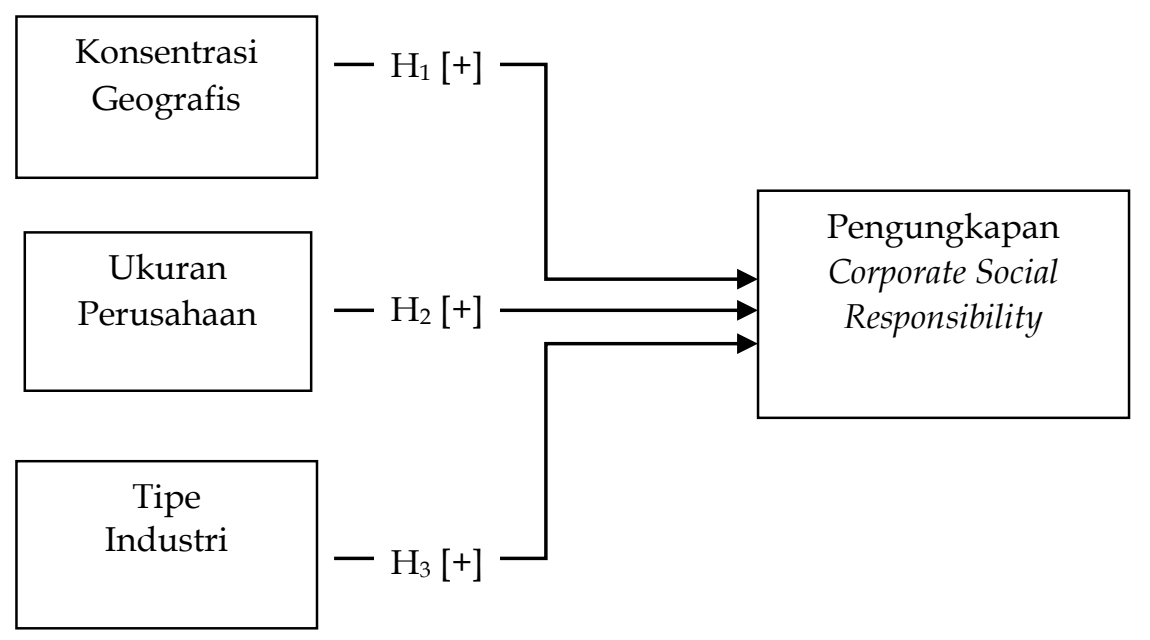

Sumber: Data Penelitian, 2020 


\section{METODE PENELITIAN}

Penelitian ini dilakukan di Bursa Efek Indonesia dengan cara mengunduh laporan tahunan dan laporan keuangan tahun 2016-2018. Data diakses melalui web www.idx.co.id dan objek penelitian yaitu pengungkapan corporate social responsibility.

Pengungkapan CSR diberi notasi CSRD, pengukuran menggunakan indeks GRI versi G4 yaitu sebanyak 91 item pengungkapan CSR yang mengacu pada tiga aspek yaitu ekonomi, lingkungan dan sosial. Penghitungan dilakukan dengan melihat ada atau tidaknya item dalam GRI G4 yang diungkapkan dalam laporan tahunan. Nilai 1 diberikan untuk item yang diungkapkan dan nilai 0 untuk item yang tidak diungkapkan (Suprasto \& Haryanti, 2019).

CSRD $=\frac{\text { Jumlah item CSR yang diungkapkan perusahaan }}{91 \text { item CSR indeks GRI G4 }}$

Konsentrasi geografis dalam penelitian ini yaitu perusahaan yang beroperasi hanya di satu negara (domestik) dan perusahaan yang beroperasi atau memiliki anak perusahaan di lebih dari satu negara (multinasional). Konsentrasi geografis diukur dengan variabel dummy. Untuk perusahaan domestik diberi angka 0 dan perusahaan multinasional diberi angka 1 (Bawono \& Haryanto, 2015). Ukuran perusahaan didefinisikan melalui total aktiva perusahaan yang diukur menggunakan log natural total aset (Urmila \& Mertha, 2017). Tipe industri diproksikan dengan perusahaan yang masuk kategori industri high profile dan low profile yang diukur memakai variabel dummy. Nilai 1 diberikan untuk perusahaan yang masuk kategori high profile dan nilai 0 untuk perusahaan yang tergolong low profile (Widiastuti et al., 2018).

Penelitian ini memakai data sekunder berupa laporan tahunan dan laporan keuangan perusahaan yang terdaftar di BEI periode 2016-2018. Populasi yang digunakan yaitu perusahaan listing di BEI yang menjadi peserta PROPER dan sampel dipilih melalui nonprobability sampling methods dengan teknik purposive sampling. Adapun kriteria sampel yang digunakan yaitu perusahaan listing di BEI yang menjadi peserta PROPER tahun 2016-2018 dan perusahaan yang menerbitkan laporan tahunan dari tahun 2016-2018 berturut-turut.

Pengumpulan data dalam penelitian ini menggunakan metode studi pustaka dan Dokumentasi. Metode Studi pustaka yaitu dengan memahami literature yang memuat pembahasan berkaitan dengan penelitian melalui artikel, jurnal maupun buku. Metode dokumentasi dengan cara mengumpulkan laporan keuangan dan laporan tahunan perusahaan. Teknik analisis data menggunakan analisis regresi linier berganda yang digunakan untuk mengetahui hubungan antara variabel bebas dan variabel terikat. Sebelum melakukan regresi, terlebih dahulu dilakukan uji asumsi klasik yang terdiri atas uji normalitas, uji multikolinearitas, uji heteroskedastisitas dan uji autokolerasi. Adapun persamaan regresi linier berganda dalam penelitian ini yaitu sebagai berikut.

$$
\mathrm{CSRD}=\alpha+\beta_{1} \mathrm{KG}+\beta_{2} \mathrm{UP}+\beta_{3} \mathrm{TI}+\varepsilon
$$

Keterangan:

$\begin{array}{ll}\text { CSRD } & =\text { pengungkapan CSR } \\ \text { KG } & =\text { konsentrasi geografis } \\ \text { UP } & =\text { ukuran perusahaan }\end{array}$




$$
\begin{aligned}
& \text { TI }=\text { tipe industri } \\
& \text { a }=\text { nilai konstanta } \\
& \beta_{1}, \beta_{2}, \beta_{3} \quad=\text { koefisien regresi } \\
& \varepsilon=\text { residual error }
\end{aligned}
$$

\section{HASIL DAN PEMBAHASAN}

Perusahaan yang menjadi sampel sesuai dengan kriteria pemilihan sampel sebanyak 46 perusahaan. Tabel 2 menyajikan hasil proses penyaringan sampel.

\section{Tabel 2. Seleksi Sampel Penelitian}

\begin{tabular}{clc}
\hline No & \multicolumn{1}{c}{ Kriteria } & Jumlah perusahaan \\
\hline 1 & Perusahaan listing di BEI yang menjadi peserta & 49 \\
& PROPER dari tahun 2016-2018 & \\
2 & $\begin{array}{l}\text { Perusahaan yang tidak menerbitkan laporan tahunan } \\
\text { dari tahun 2016-2018 berturut-turut }\end{array}$ & (3) \\
& Jumlah sampel perusahaan & 46 \\
& Jumlah observasi selama 3 tahun & 138 \\
\hline
\end{tabular}

Sumber: www.idx.co.id, diakses 06 November 2019

Statistik deskriptif digunakan mengetahui karakteristik sampel. Tabel 3, menyajikan hasil statistik deskriptif.

Tabel 3. Statistik Deskriptif

\begin{tabular}{lrrrrr}
\hline & & Minimum & Maximum & Mean & Std. Deviation \\
\hline CSRD & 138 & 0,00 & 0,44 & 0,24 & 0,11 \\
KG & 138 & 0 & 1 & 0,74 & 0,44 \\
UP & 138 & 27,18 & 32,39 & 29,71 & 1,39 \\
TI & 138 & 0 & 1 & 0,72 & 0,45 \\
Valid N & 138 & & & & \\
$\quad$ (Listwise) & & & & & \\
\hline
\end{tabular}

Sumber: Data Penelitian, 2020

Indeks pengungkapan CSR memiliki rata-rata (mean) 0,24 atau $24 \%$ yang menunjukkan dalam satu periode laporan tahunan, perusahaan rata-rata telah melakukan pengungkapan sebanyak $24 \%$ atau sekitar 21 hingga 22 item CSR. Indeks pengungkapan paling kecil (minimum) sebesar 0,00 dan indeks pengungkapan paling besar (maximum) sebesar 0,44 serta deviasi standar sebesar 0,11 .

Nilai rata-rata untuk variabel konsentrasi geografis yaitu 0,74. Nilai terkecil sebesar 0 dan nilai terbesar yaitu 1 dengan deviasi standar sebesar 0,44. Variabel ukuran perusahaan menunjukkan rata-rata sebesar 29,71. Nilai terkecil sebesar 27,18 dan nilai terbesar yaitu 32,39 dengan deviasi standar sebesar 1,39. Variabel tipe industri mempunyai rata-rata sebesar 0,72 . Nilai terkecil sebesar 0 , nilai terbesar yaitu 1 dan deviasi standar sebesar 0,45.

Sebagai syarat analisis regresi linier berganda, dilakukan uji asumsi klasik yang terdiri atas uji normalitas, uji multikolinieritas, uji heteroskedastisitas, dan uji autokorelasi. Uji normalitas yang digunakan adalah uji Kolmogorov-Smirnov. Tabel 4 menyajikan hasil uji normalitas. Nilai Asymp. Sig. (2-tailed) lebih besar dari 0,05 yaitu sebesar 0,20. Dapat disimpulkan bahwa syarat normalitas terpenuhi. 
Tabel 4. Hasil Uji Normalitas

\begin{tabular}{lr}
\hline & Unstandardized \\
Residual \\
\hline Normal Parameters Mean & 138 \\
Standard Deviation & 0,00 \\
Most Extreme Differents Absolut & 0,09 \\
Positive & 0,06 \\
Negative & 0,04 \\
Test Statistic & $-0,06$ \\
Asymp. Sig. (2-tailed) & 0,06 \\
\hline
\end{tabular}

Sumber: Data Penelitian, 2020

Uji multikolinearitas digunakan untuk mengetahui adanya kolerasi antar variabel bebas. Tabel 5, menyajikan hasil uji multikolinearitas. Setiap variabel bebas memiliki nilai tolerance lebih dari 0,1 dan nilai VIF kurang dari 10, maka diputuskan tidak terjadi masalah multikolinearitas.

Tabel 5. Hasil Uji Multikolinearitas

\begin{tabular}{lrr}
\hline \multicolumn{1}{c}{ Variabel } & Tolerance & VIF \\
\hline Konsentrasi Geografis (KG) & 0,98 & 1,02 \\
Ukuran Perusahaan (UP) & 1,00 & 1,00 \\
Tipe Industri (TI) & 0,97 & 1,03 \\
\hline
\end{tabular}

Sumber: Data Penelitian, 2020

Uji heteroskedastisitas digunakan untuk mengetahui adanya ketidaksamaan varians dalam residual regresi. Tabel 6, menyajikan hasil uji heteroskedastisitas menggunakan uji glejser. Nilai signifikansi masing-masing variabel berada diatas 0,05 sehingga tidak terjadi masalah heteroskedastisitas.

Tabel 6. Hasil Uji Heteroskedastisitas

\begin{tabular}{lc}
\hline \multicolumn{1}{c}{ Variabel } & Sig. \\
\hline Konsentrasi Geografis (KG) & 0,08 \\
Ukuran Perusahaan (UP) & 0,10 \\
Tipe Industri (TI) & 0,98 \\
\hline
\end{tabular}

Sumber: Data Penelitian, 2020

Uji autokolerasi dilakukan dengan mengamati kolerasi antara residual pada suatu periode dengan residual pada periode sebelumnya. Tabel 7, menunjukkan hasil uji autokolerasi. Nilai Durbin-Watson (DW) sebesar 1,92 dengan signifikansi 0,05 dan $\mathrm{n}=138$ serta $\mathrm{k}=3$ memiliki nilai $\mathrm{dL}=1,68$ dan nilai $\mathrm{dU}=1,77$. Nilai DW ini memenuhi syarat $\mathrm{dU}<\mathrm{DW}<(4-\mathrm{dU})$ yaitu $1,77<1,92<$ 2,33 sehingga dapat dinyatakan penelitian ini terbebas dari masalah autokolerasi. Tabel 7. Hasil Uji Autokolerasi

\begin{tabular}{cccrrr}
\hline Model & $\mathrm{R}$ & $\mathrm{R}^{2}$ & Adjusted $R^{2}$ & Std. Error of the Estimate & Durbin-Watson \\
\hline 1 & 0,59 & 0,34 & 0,33 & 0,09 & 1,92 \\
\hline
\end{tabular}

Sumber: Data Penelitian, 2020

Analisis regresi linier berganda dilakukan untuk mengetahui hubungan variabel dependen dengan variabel independen. Tabel 8 menunjukkan konsentrasi geografis dan ukuran perusahaan berpengaruh positif sedangkan tipe industri tidak memiliki pengaruh, sehingga persamaan yang dapat disusun yaitu:

$$
\mathrm{CSRD}=-0,94+0,08 \mathrm{KG}+0,04 \mathrm{UP}+\varepsilon
$$


Tabel 8. Hasil Analisis Regresi Linear Berganda

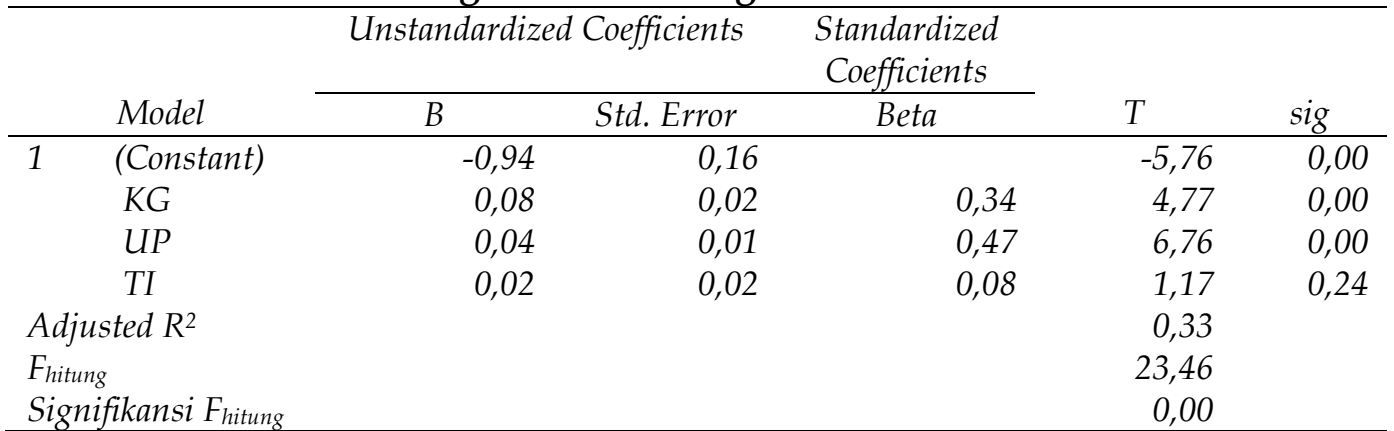

Sumber: Data Penelitian, 2020

Hasil analisis regresi linier berganda memperlihatkan nilai F-hitung sebesar 23,46 dengan signifikansi 0,00. Hal ini menunjukkan model penelitian ini layak atau variabel konsentrasi geografis, ukuran perusahaan dan tipe industri dapat menerangkan variabel pengungkapan corporate social responsibility.

Koefisien determinasi digunakan untuk mengetahui seberapa besar variabel independen dapat menerangkan variasi variabel dependen dalam persamaan regresi yang diteliti. Adjusted $R^{2}$ sebesar 0,33 berarti bahwa $33 \%$ variasi pengungkapan CSR dapat diterangkan oleh variabel konsentrasi geografis dan ukuran perusahaan, sedangkan sisanya $67 \%$ dijelaskan oleh variabel lain di luar model.

Hipotesis pertama menyatakan konsentrasi geografis berpengaruh positif pada pengungkapan CSR. Koefisien regresi variabel konsentrasi geografis (KG) sebesar 0,08 dan tanda koefisien regresi positif. Nilai signifikansi variabel konsentrasi geografis adalah 0,00. Nilai ini lebih kecil dari 0,05 maka dapat disimpulkan bahwa konsentrasi geografis memiliki pengaruh positif pada pengungkapan CSR.

Perusahaan multinasional dalam menjalankan bisnisnya sangat membutuhkan legitimasi dari masyarakat yang ada di negara tempat perusahaan multinasional tersebut berada. Perusahaan multinasional memiliki informasi tanggung jawab sosial yang lebih banyak karena persaingan yang lebih ketat sehingga kelangsungan hidup perusahaan tidak hanya dari keuntungan tetapi juga harus memiliki keunggulan di bidang sosial guna menjaga legitimasi. Perusahaan multinasional juga menghadapi tekanan yang lebih besar untuk menyesuaikan diri agar dapat bertahan dengan kondisi lingkungan yang berbedabeda di setiap negara. Jika dikaitkan dengan teori legitimasi maka perusahaan multinasional harus menyesuaikan diri dengan nilai sosial yang ada di negara tempatnya berada agar tetap bisa bertahan, sehingga pengungkapan CSR menjadi hal yang penting bagi perusahaan multinasional. Hasil ini sejalan dengan penelitian Aksak \& Duman (2016), yang menemukan perusahaan multinasional berpengaruh pada pengungkapan CSR.

Hipotesis kedua menyatakan ukuran perusahaan berpengaruh positif pada pengungkapan CSR. Koefisien regresi variabel ukuran perusahaan (UP) adalah 0,04 dan tanda koefisien positif. Nilai signifikansi variabel ukuran perusahaan adalah 0,00. Nilai ini lebih kecil dari 0,05 sehingga dapat disimpulkan bahwa ukuran perusahaan memiliki pengaruh positif pada pengungkapan CSR. 
Hal ini menunjukkan bahwa semakin besar ukuran perusahaan maka semakin banyak item CSR yang diungkapkan dalam annual report. Perusahaan besar mempunyai aktivitas yang lebih banyak serta dampak operasional yang lebih besar, hal ini menyebabkan perusahaan mendapat tekanan dari masyarakat untuk mengungkapkan informasi CSR sebagai bentuk tanggung jawab kepada masyarakat.

Sesuai teori legitimasi perusahaan akan mencoba menyelaraskan nilai kegiatannya dengan nilai sosial masyarakat agar tetap mendapat legitimasi. Perusahaan besar perlu menyelaraskan dampak dari kegiatan operasional perusahaan dengan keinginan masyarakat sehingga penting untuk memberikan informasi tentang corporate social responsibility yang lebih luas agar tetap mendapat legitimasi dari masyarakat. Hasil ini sesuai dengan penelitian Irham et al. (2018), Ramadhani \& Agustina (2019) serta Solikhah (2016) yang menemukan bahwa perusahaan besar mengungkapkan lebih banyak item CSR.

Hipotesis ketiga menyatakan tipe industri berpengaruh positif pada pengungkapan CSR. Nilai signifikansi variabel tipe industri yaitu 0,24. Nilai ini lebih besar dari 0,05 sehingga tipe industri tidak memiliki pengaruh pada pengungkapan CSR. Hasil penelitian ini bertentangan dengan penelitian Widiastuti et al. (2018) yang menemukan tipe industri berpengaruh positif pada pengungkapan CSR, namun sesuai dengan penelitian oleh Al-Ajmi et al. (2015) dan Novrizal \& Fitri (2016) yang menyatakan tidak ada hubungan antara kedua variabel tersebut.

Nisak \& Jaeni (2019) mengungkapkan tidak berpengaruhnya tipe industri pada pengungkapan CSR kemungkinan disebabkan oleh tekanan masyarakat yang tidak berpusat pada perusahaan dengan jenis industri tertentu saja. Masyarakat akan memberikan tekanan kepada semua perusahaan yang tidak berusaha mengendalikan dampak sosial dan lingkungannya. Perusahaan yang menerima tekanan ini akan melaksanakan tanggung jawab sosial dan mengungkapkannya sebagai bentuk tanggung jawab untuk tetap mendapat legitimasi masyarakat.

\section{SIMPULAN}

Hasil penelitian ini menunjukkan konsentrasi geografis dan ukuran perusahaan berpengaruh positif sedangkan tipe industri tidak berpengaruh pada pengungkapan CSR. Konsentrasi geografis dan ukuran perusahaan berhasil memberikan bukti berlakunya teori legitimasi, sedangkan variabel tipe industri tidak berhasil memberikan bukti berlakunya teori legitimasi sebagai teori yang mendasari penelitian ini.

Nilai adjusted $R^{2}$ yang tergolong rendah yaitu sebesar 0,33 atau $33 \%$ menunjukkan bahwa masih banyak faktor lain yang memengaruhi pengungkapan CSR selain konsentrasi geografis dan ukuran perusahaan. Peneliti berikutnya dapat memperluas penelitian dengan menambahkan faktor lain yang berpotensi memengaruhi pengungkapan CSR.

Berdasarkan hasil penelitian, perusahaan multinasional dan perusahaan besar mengungkapkan lebih banyak item CSR dalam laporan tahunan. Untuk itu pemerintah diharapkan dapat mendorong perusahaan domestik dan perusahaan kecil agar mempunyai semangat yang sama dalam mengungkapkan CSR. 
Pemerintah juga dapat membuat pedoman yang mengatur pengungkapan CSR secara rinci sehingga memudahkan perusahaan dalam mengungkapkan item CSR.

\section{REFERENSI}

Aksak, E. O., \& Duman, S. A. (2016). Gaining legitimacy through CSR: An analysis of Turkey's 30 largest corporations. Business Ethics: A European Review, 25(3). https://doi.org/10.1111/beer.12114.

Al-Ajmi, M., Al-Mutairi, A., \& Al-Duwaila, N. (2015). Corporate Social Disclosure Practices in Kuwait. International Journal of Economics and Finance, 7(9), 244254. https:// doi.org/10.5539/ijef.v7n9p244.

Al-Gamrh, B. A., \& AL-Dhamari, R. A. (2016). Firm Characteristics and Corporate Social Responsibility Disclosure. International Business Management, 10 (18), 4283-4291. http://docsdrive.com/pdfs/medwelljournals/ibm/2016/42834291.pdf.

Anggraeni, D. Y., \& Djakman, C. D. (2018). Pengujian Terhadap Kualitas Pengungkpan CSR Di Indonesia. Ekuitas: Jurnal Ekonomi Dan Keuangan, 2(1), 22-41. https:// doi.org/10.24034/j25485024.y2018.v2.i1.2457.

Bawono, A. A. K., \& Haryanto. (2015). Pengaruh Ukuran Perusahaan, Leverage, Profitabilitas, Cakupan Operasional Perusahaan, Dan Sertifikasi ISO 14001 Terhadap Pengungkapan Corporate Social Responsibility. Diponegoro Journal Of Accounting 4(3), 1-12.

Bursa Efek Indonesia. (2019). Laporan Tahunan Perusahaan Tercatat. Diakses 06 November 2019, dari www.idx.co.id.

Dewanti, R. L., \& Widyadmono, V. M. (2018). The impact of type of industry, company size and leverage on the disclosure of corporate social responsibility: Case on Companies listed in Indonesia Stock Exchange 20092012. The International Journal of Social Science, Education and Human Science UTY, 1(1), 36-50.

Dowling, J., \& Pfeffer, J. (1975). Organizational legitimacy: Social values and organizational behavior. Sociological Perspectives, 18(1), 122-136. https://doi.org/10.2307/1388226.

Elshabasy, Y. N. (2018). The impact of corporate characteristics on environmental information disclosure: An empirical study on the listed firms in Egypt. Journal of Business and Retail Management Research, 12(2), 232-241. https://doi.org/10.24052/jbrmr/v12is02/tioccoeidaesotlfie.

Gunawan, G., \& Apriwenni, P. (2019). Faktor-Faktor Yang Memengaruhi Pengungkapan Tanggung Jawab Sosial Pada Perusahaan Dibidang Pertambangan Yang Terdaftar Di Bursa Efek Indonesia. Jurnal Akuntansi Manajemen, 8(1), 38-54.

Hidayat, W. W. (2017). The Influence of Size, Return on Equity, and Leverage on the disclosure of the Corporate Social Responsibility (CSR ) in Manufacturing Companies. International Journal of Education and Research, 5(8), 57-66.

Indraswari, G. A. D., \& Astika, I. B.P. (2015). Pengaruh Profitabilitas, Ukuran Perusahaan, dan Kepemilikan Saham publik Terhadap Pengungkapan CSR. E-Jurnal Akuntansi Universitas Udayana, 11(1), 289-302.

Indrayenti, \& Jenny. (2018). Analisis Pengaruh Ukuran Perusahaan, Ukuran Dewan Komisaris, Profitabilitas, Dan Leverage Terhadap Pengungkapan 
Tanggung Jawab Sosial Pada Sektor Industri Barang Konsumsi Yang Terdaftar Di Bursa Efek Indonesia Periode 2014-2016. Jurnal Akuntansi $\mathcal{E}$ Keuangan, 9(2), 1-13. https:/ / doi.org/10.1590/s1809-98232013000400007.

Irham, A. R., Yuliana, S., \& Widiyanti, M. (2018). The effect firm characteristic on corporate social responsibility disclosure in the firms listed in Indonesia Sharia Stock Index. Jurnal Perspektif Pembiayaan Dan Pembangunan Daerah, 6(3), 303-318. https://doi.org/10.22437/ppd.v6i3.5820.

Issa, A. I. F. (2017). The Factors Influencing Corporate Social Responsibility Disclosure in the Kingdom of Saudi Arabia. Australian Journal of Basic and Applied Sciences, 11(10), 1-19.

Kementrian Lingkungan Hidup dan Kehutanan. (2019). Program Penilaian Kinerja Perusahaan (PROPER). Diakses 02 Oktober 2019. Dari http:// proper.menlhk.go.id.

Kopel, M., Manasakis, C. \& Petrakis, E. (2018). Strategic corporate social responsibility by a local firm against a multinational enterprise. Springer Proceedings in Complexity, (246), 178-191. https:// doi.org/10.1007/978-3-31965627-4_10.

Kusumawardani, I., \& Sudana, I. P. (2017). Faktor-Faktor Yang Mempengaruhi Pengungkapan Corporate Social Responsibility. E-Jurnal Akuntansi Universitas Udayana, 19 (1), 741-770. https://doi.org/10.25139/jaap.v1i2.144.

Nisak, K., \& Jaeni. (2019). Faktor Penentu Pengungkapan Corporate Social Responsibility (Studi Empiris pada Perusahaan Manufaktur yang Terdaftar di Bursa Efek Indonesia). Dinamika Akuntansi, Keuangan dan Perbankan, 8 (1), Hal: $36-50$

Novrizal, M. F., \& Fitri, M. (2016). Faktor-Faktor yang Mempengaruhi Pengungkapan Corporate Social Responbility (CSR) pada Perusahaan yang Terdaftar di Jakarta Islamic Index ( JII ) tahun 2012- 2015 dengan Menggunakan Islamic Social Reporting (ISR) Index sebagai Tolok Ukur. Jurnal Ilmiah Mahasiswa Ekonomi Akuntansi (JIMEKA), 1(2), 177-189.

Oktariani, N. W, \& Mimba, N. P. S. H. (2014). Pengaruh Karakteristik Perusahaan Dan Tanggung Jawab Lingkungan Pada Pengungkapan Tanggung Jawab Sosial Perusahaan. E-Jurnal Akuntansi Universitas Udayana, 6(3), 402-418.

Ramadhani, C. F., \& Agustina, L. (2019). Influence of Company Characteristics on Corporate Social Responsibility Disclosures in the Annual Reports of the Manufacturing Companies. Accounting Analysis Journal 8(1), 24-30. https://doi.org/10.15294/aaj.v8i1.28614.

Respati, R. D., \& Hadiprajitno, P. B. (2015). Analisis Pengaruh Profitabilitas, Leverage, Ukuran Perusahaan, Tipe Industri, Dan Pengungkapan Media Terhadap Pengungkapan Corporate Social Responsibility. Diponegoro Journal of Accounting, 4(4), 1-11.

Riantani, S., \& Nurzamzam, H. (2015). Analysis of Company Size, Financial Leverage, and Profitability and Its Effect To CSR Disclosure. Jurnal Dinamika Manajemen, 6(2), 203-213. https://doi.org/10.15294/jdm.v6i2.4308.

Solikhah, B. (2016). An overview of legitimacy theory on the influence of company size and industry sensitivity towards CSR disclosure. IJABER, 14(5), 30133023. 
Suprasto, H. B., \& Haryanti, A. P. S. (2019). Pengaruh Karakteristik Perusahaan Pada Pengungkapan Tanggung Jawab Sosial Perusahaan. Jurnal Ilmiah Akuntansi Dan Bisnis, 14(2). https:// doi.org/10.24843/jiab.2019.v14.i02.p07.

Susilowati, F., Zulfa, K., \& Hartono, A. (2018). Pengaruh Ukuran Perusahaan, Profitabilitas, Leverage, Tipe Industri, Dan Ukuran Dewan Komisaris Terhadap Corporate Social Responsibility Disclosure. Jurnal Ekonomi, Manajemen Dan Akuntansi, Volume 2 (1), 15-25.

Tetrevova, L. (2018). Communicating CSR in high profile industries: Case study of Czech chemical industry. Inzinerine Ekonomika-Engineering Economics, 29(4), 478-487. https:/ / doi.org/10.5755/j01.ee.29.4.19199.

Titisari, K. H. (2017). Praktek Corporate Social Responsibility (CSR) Di Perusahaan Multinasional. Riset Akuntansi Dan Keuangan Indonesia, 2(1). https://doi.org/10.23917/ reaksi.v2i1.3497.

Urmila, N. M. D., \& Mertha, M. (2017). Tipe Perusahaan Memoderasi Ukuran Perusahaan, Profitabilitas, Kepemilikan Asing pada Pengungkapan CSR Perusahaan Manufaktur di BEI. E-Jurnal Akuntansi Universitas Udayana, 19(3), 2145-2174.

Waluyo, W. (2017). Firm size, firm age, and firm growth on corporate social responsibility in Indonesia: The case of real estate companies. European Research Studies Journal, 20(4), 360-369.

Widiastuti, H., Utami, E. R., \& Handoko, R. (2018). Pengaruh Ukuran Perusahaan, Tipe Industri, Growth, Dan Media Exposure Terhadap Pengungkapan Tanggung Jawab Sosial Perusahaan (Studi Empiris pada Perusahaan yang Terdaftar di Bursa Efek Indonesia Tahun 2014-2015). Riset Akuntansi Dan Keuangan Indonesia, 3(2), 107-117. https:/ / doi.org/10.23917/reaksi.v3i2.6745.

Wiyuda, A., \& Pramono, H. (2017). Pengaruh Good Corporate Governance, Karakteristik Perusahaan Terhadap Luas Pengungkapan Corporate Social Responsibility Pada Perusahaan Terdaftar Di BEI. Kompartemen, XV(1), 12-25. 